\title{
Clinical, radiological, and auxological characteristics of patients with cleidocranial dysplasia followed in a pediatric referral hospital in Argentina
}

\author{
Rosario Ramos Mejía, M.D. ${ }^{a}$, Mercedes Rodríguez Celin, M.D. ${ }^{a}$ and Virginia Fano M.D. ${ }^{a}$
}

\begin{abstract}
Cleidocranial dysplasia is an autosomal dominant skeletal dysplasia caused by mutations in the RUNX2 gene; its prevalence has been estimated at $1 / 1000000$ newborn infants. This study presents 37 patients (22 girls) assessed between 1992 and 2016 at the Skeletal Dysplasias Multidisciplinary Clinics of Hospital Garrahan, Argentina. Findings: $35 \%$ of positive family history; median age at the time of diagnosis: 2.61 years old; positive radiological findings in the skull and pubis: $95 \%$; in the clavicles: $100 \%$. Dental and hearing complications were common. Auxology: boys had a median height of $-1.81 \mathrm{SD}$ (-3.26 to 0.2) and girls had a median height of -1.36 SD (-4.28 to 1.36). Five out of 13 patients were short for parental height. Adult height (median): $162.8 \mathrm{~cm}$ in boys and $149.2 \mathrm{~cm}$ in girls. No evident alterations were observed in the sitting height/ height ratio. One patient had true macrocephaly; $12(32 \%)$, relative macrocephaly. Intrafamily variability was described in terms of height. Key words: cleidocranial dysplasia, growth, clavicle, cranial fontanelles.
\end{abstract}

http: / / dx.doi.org/10.5546/ aap.2018.eng.e560

To cite: Ramos Mejía R, Rodríguez Celin M, Fano V. Clinical, radiological, and auxological characteristics of patients with cleidocranial dysplasia followed in a pediatric referral hospital in Argentina. Arch Argent Pediatr 2018;116(4):e560-e566.

a. Skeletal Dysplasia Multidisciplinary Clinics, Hospital Garrahan, Autonomous City of Buenos Aires, Argentina.

E-mail address:

Rosario Ramos Mejía, M.D.: rosariorm@gmail. com

Funding:

None.

Conflict of interest: None.

Received: 9-6-2017

Accepted: 1-22-2018

\section{INTRODUCTION}

Cleidocranial dysplasia (CCD) (MIM 119600) is a skeletal dysplasia characterized by persistent fontanelles and aplasia/hypoplasia of the clavicles, with a wide phenotypic variability. ${ }^{1,2}$ The affected population has been described to have moderate short stature, ${ }^{1,3-5}$ but few data have been reported regarding other auxological outcome measures.

Its prevalence is $1 / 1000000$ births, regardless of sex. ${ }^{4}$

CCD is caused by autosomal dominant inherited mutations in the RUNX2 (runt-related transcription factor 2) gene found on the short arm of the chromosome $6 .^{1,2,4,6}$ Insertions, deletions, nonsense mutations, and missense mutations have been identified.$^{6-10}$ In most patients, these are de novo mutations. ${ }^{4}$ Germline mosaicism has also been proposed. ${ }^{1}$ Pathogenic variants have been observed in $60-70 \%$ of patients with clinical diagnosis. ${ }^{4}$

The RUNX2 gene encodes the Cbfa1 transcription factor, which is essential for osteoblast differentiation and skeletal morphogenesis, and is involved in intramembranous and endochondral ossification. RUNX2 gene mutations result in a disorder that combines isolated bone defects (dysostosis) with progressive tissue defects (dysplasia). ${ }^{2}$

Clinical and laboratory characteristics overlapping with hypophosfatasia have been described in a small subgroup of patients, possibly due to an alteration in the expression of the TNSALP (tissuenonspecific alkaline phosphatase) gene..$^{2,5,11,12} R U N X 2$ knockout mice show a complete lack of bone mineralization and absence of TNSALP expression. ${ }^{13}$ 
The diagnosis of CCD is based on clinical and radiological findings. ${ }^{1,2,4}$ The differential diagnoses should include hypothyroidism, congenital pseudarthrosis of the clavicle (MIM 118980), and other skeletal dysplasias. ${ }^{1,4}$

Follow-up has been recommended to look for orthopedic, dental, and hearing complications, sinus and middle ear infections, upper airway obstruction, and osteoporosis.,4 Although some authors have reported a delay in motor milestone achievement, ${ }^{3,4}$ education, life expectancy, and functions are normal. ${ }^{2,3}$

\section{OBJECTIVES}

To provide a clinical and auxological description of patients diagnosed with CCD.

\section{MATERIALS AND METHODS}

The medical records of patients with a clinical and radiological diagnosis of CCD were reviewed. This retrospective study was based on data about children, and their parents, assessed between 1992 and 2016 at the Skeletal Dysplasia Multidisciplinary Clinics of Hospital "Prof. Dr. Juan P. Garrahan," Argentina.

The following outcome measures were considered: age, age at the time of diagnosis, sex, reason for consultation, affected family members, weight, body length, height, sitting height, head circumference, and the presence of associated complications.

The same observer conducted the anthropometric measurements at the anthropometry laboratory of the Department of Growth and Development using the standardized techniques recommended by the Sociedad Argentina de Pediatría, (SAP). ${ }^{14}$

Harpenden instruments were used to measure body length, vertex - buttocks length, height, and sitting height. A lever scale was used to measure weight. Intraobserver measurement errors were $0.11 \mathrm{~cm}, 0.10 \mathrm{~cm}$, and $0.10 \mathrm{~kg}$ for body length, height, and weight, respectively.

Weight and body length at birth were obtained from the birth records of patients, if available.

Adult family members were considered for the analysis of final height.

Standard deviation scores (SD) were estimated for anthropometric data. Height and body proportions (sitting height/height and head circumference/height) were compared to Argentine standards; ${ }^{15-16}$ British data from 1990 were used to assess head circumference. ${ }^{17}$ Body mass index (BMI) values were compared to data from a multicenter study carried out by the World Health Organization (WHO) in children younger than 5 years and data from the Centers for Disease Control and Prevention (CDC) corresponding to children older than 5 years. ${ }^{18,19}$

The midparental height (MPH) was estimated if both parents were not affected, and described as $\mathrm{SD}: \mathrm{MPH}=(\mathrm{HZsF}+\mathrm{HZsM}) / 2$, where $\mathrm{HZsF}$ means the height Z-score of the father and HZsM is the height Z-score of the mother, considering $\mathrm{MPH} \pm 1.28 \mathrm{SD}$ as the normal genetic range in prepubertal children. ${ }^{20}$

Patients were considered to have reached their final height once they had reached their adult pubertal development (Tanner stage $\mathrm{V}$ breast development or two years after the menarche in girls; $15-\mathrm{mL}$ testicular volume in boys).

Radiological diagnosis was confirmed by two of the authors (MRC and RRM). The diagnostic criteria for each radiological characteristic were as follows: presence of Wormian bones if the frequency of these bones was 10 or more, ${ }^{21}$ delayed closure of the anterior fontanelle if it remained open after 2 years old, ${ }^{22}$ hypoplasia of the clavicles if the lateral half of the clavicle was absent, ${ }^{22}$ delayed pubic bone ossification if they were not ossified after 6 months old, and lack of ischiopubic branches fusion if there was no fusion in patients aged 12 years and older, ${ }^{22-24}$ hand anomalies in the presence of delayed carpal bone ossification or if there were cone-shaped epiphyses or pseudoepiphyses. $^{2}$

Complications were considered if registered in the medical record.

\section{RESULTS}

The study included 37 patients with CCD; $59 \%$ were girls $(n=22)$. Patients' median age was 1.59 years ( 0 to 16.09 ) at the first visit and 2.61 years ( 0 to 16.09 ) at the time of diagnosis. Patients were followed for a median of 3.67 years (0 to 12.67$)$. In $35 \%$ of cases $(n=13)$, other family members were affected.

The two main reasons for consultation were skull anomalies (skull asymmetry, broad fontanelle, diastasis of the cranial sutures) in 51\% of cases $(n=19)$ and suspected skeletal dysplasia in $19 \%(n=7,2$ of them had suspected CCD). Other reasons included coxa vara or valga $(n=6)$, short stature $(n=4)$, scoliosis $(n=2)$, clavicle alterations $(n=2)$, hypotonia $(n=1)$, and delayed motor milestone achievement $(n=1)$. Some patients had more than one reason for referral. 
Table 1 shows the clinical findings; data are compared to the bibliography.

\section{AUXOLOGICAL ANALYSIS Boys $(n=15)$}

The records of anthropometric measurements at birth were available for four patients. One patient had intrauterine growth restriction (IUGR) in terms of weight, body length, and head circumference for no attributable reason.

Figure 1. A shows the height distance curve for boys; it is evident that all, except one, have a normal growth pattern. This patient is being studied for delayed growth; his laboratory parameters are normal. At the last visit, the median height was $-1.81 \mathrm{SD}(-3.26$ to 0.2$)$ and the median age, 6.43 years (0.92 to 16.79). Among the patients for whom parental height was reported $(n=8)$, the median differences between MPH in SD and boys' height in SD was -1.12 SD (-2.03 to 1.44); three patients were short and one was tall for their parents' height.

The median head circumference at the last visit was -0.85 SD (-2.23 to 0.81$)$. No boy had true macrocephaly; however, all but one $(n=14)$ were above the $50^{\text {th }}$ centile in the head circumference curve. As shown in Figure 2.A, seven patients had relative macrocephaly.
Patients did not show alterations in the sitting height/height ratio.

The BMI at the last visit was -0.36 SD (-2.41 to 1.19). One patient was thin and another, overweight.

\section{Girls ( $=22)$}

The records of anthropometric measurements at birth were available for half of the patients $(n=11)$. Only one girl had IUGR in terms of body length and head circumference for no attributable reason.

Figure 1.B shows the height distance curve for girls; at the last visit, the median height was $-1.36 \mathrm{SD}(-4.28$ to 1.36$)$ and the median age, 5.70 years ( 0.44 to 19.0$)$. One girl had extremely short stature and normal laboratory values. Among patients for whom parental height was reported $(n=5)$, the median differences between $\mathrm{MPH}$ in SD and girls' height in SD was -0.88 SD $(-2.88$ to 0.78$)$. Two patients were short for their parents' height.

The head circumference at the last visit was -0.04 SD (-3.47 to 2.4). Most girls $(n=19)$ were above the $50^{\text {th }}$ centile in the head circumference curve; one had true macrocephaly. The head circumference/height chart (Figure 2.B) shows that five girls had relative macrocephaly.

No alterations were observed in the sitting height/height ratio.

TABLE 1. Clinical characteristics of the sample (37 patients). Findings reported in the bibliography ${ }^{3,25}$

\begin{tabular}{|c|c|c|c|}
\hline \multicolumn{2}{|c|}{ Clinical characteristics } & $\begin{array}{c}\text { Cases }(\mathrm{n}=37) \\
\% \\
\end{array}$ & $\begin{array}{c}\operatorname{Cooper}^{3}(\mathrm{n}=283), \\
\operatorname{Golan}^{25}(\mathrm{n}=90) \\
\%\end{array}$ \\
\hline \multirow[t]{3}{*}{ Dento-maxillary } & $\begin{array}{l}\text { Delayed primary and secondary eruption, } \\
\text { hypoplastic teeth, enamel defects }\end{array}$ & 73 & 98 \\
\hline & Archea palate & 8 & \\
\hline & Cleft of the soft palate & 3 & 4,4 \\
\hline \multirow[t]{2}{*}{ Hearing } & $\begin{array}{l}\text { Pathological audiometry } \\
\text { or otoacoustic emissions }\end{array}$ & 30 & 38 \\
\hline & Language delay & 8 & \\
\hline \multirow[t]{3}{*}{ Upper airways } & Chronic otitis media & 14 & 62 \\
\hline & Chronic sinusitis $^{34,4}$ & 11 & 34.4 \\
\hline & Rhonchopathy/adenotonsillectomy & 11 & 8 \\
\hline Respiratory & Recurrent bronchospasm & 19 & 11 \\
\hline \multirow[t]{3}{*}{ Orthopedics } & $\begin{array}{l}\text { Hip anomaly } \\
\text { (8 coxa vara, } 1 \text { coxa valga) }\end{array}$ & 24 & \\
\hline & Scoliosis & 16 & 17 \\
\hline & $\begin{array}{l}\text { Pectus deformity } \\
\text { (6 pectus excavatum, } 1 \text { pectus carinatum) }\end{array}$ & 19 & \\
\hline Education & & normal & \\
\hline
\end{tabular}


The BMI at the last visit was $0.23 \mathrm{SD}(-1.46$ to 1.6). One girl was overweight.

\section{Final height}

The data about adult height were available for four boys (two patients who reached maturity and two affected fathers); their median height was $162.8 \mathrm{~cm}$, which corresponded to -1.47 SD $(-2.41$ to -0.67) (Figure 1.A).

The data about adult height were available for seven girls (four patients who reached maturity and three affected mothers). The median height was $149.2 \mathrm{~cm}$, corresponding to $-1.89 \mathrm{SD}$ (-3.45 to 0.62) (Figure 1.B).

Although data were scarce, the comparison of height between affected parents and their children indicated that there could be intrafamily variability. In 5/10 cases, differences were observed between the father/mother's height and that of his/her child of more than 1 SD

Figure 1 ( $A$ and $B)$. Height curves for boys and girls, respectively

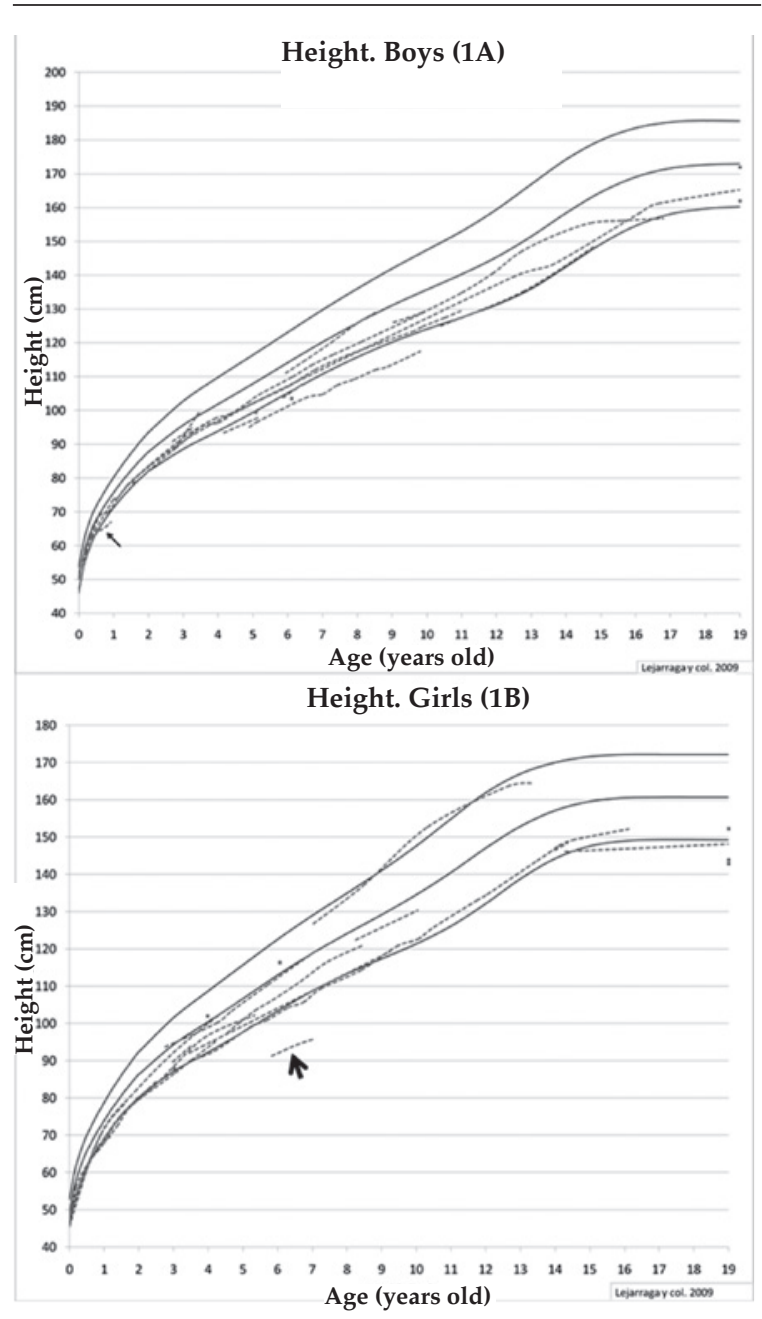

(Table 2). In a family with six affected members, the variability in height ranged between -0.74 and -2.05 SD (Figure 3).

\section{Radiological findings}

The radiological characteristics of CCD were positive in a high number of studied $X$-rays: skull anomalies were observed in $95 \%$; clavicle alterations, in $100 \%$ (both clavicles in $75 \%$ ); delayed pubic bone ossification, in $96 \%$; and hand alterations, in $100 \%$ of patients (Figure 4, Images 1, 2,3 , and 4 ).

\section{DISCUSSION}

Our study provides a longitudinal description of the auxological characteristics of a series of patients with CCD. Out of a total of 1409 patients assessed between 1992 and 2016 at the Skeletal Dysplasias Multidisciplinary Clinics of Hospital Garrahan, 37 (2.7\%) were diagnosed with CCD.

Their median age at the time of diagnosis was 2.61 years. No patient had had an antenatal diagnosis of CCD, although some had a family history. This is consistent with the bibliography, where the early diagnosis of CCD has been described to be difficult because of the often mild manifestations due to its wide phenotypic variability. ${ }^{2}$

FIGURE 2 ( $A$ and B). Head circumference/height curves for boys and girls, respectively
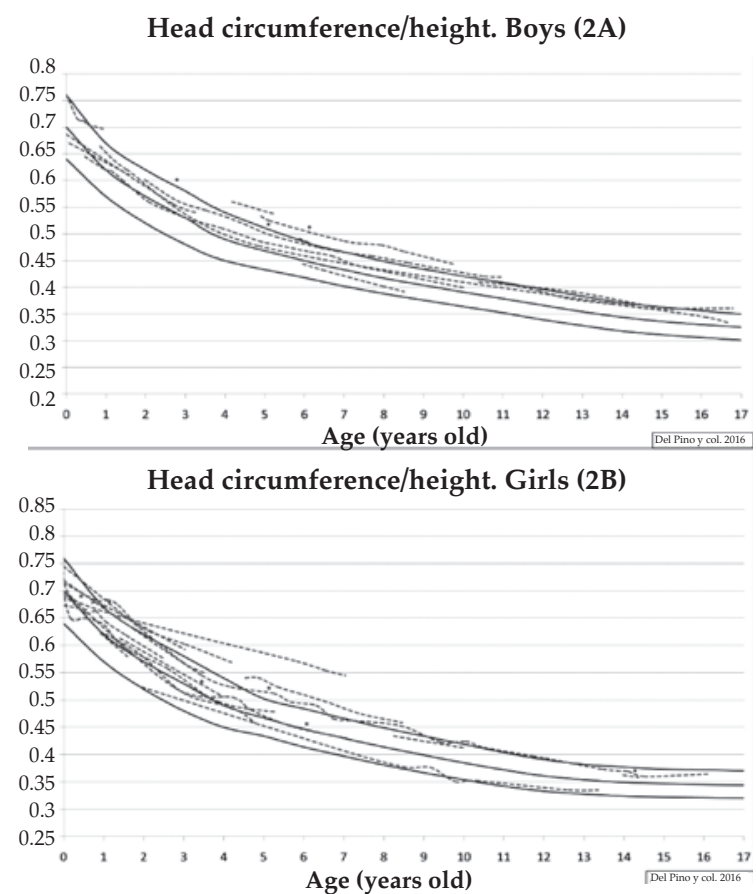
Similar to what has been mentioned in the bibliography, dental anomalies, upper airway and hearing disorders were frequent. ${ }^{1,3,4,25}$ Other described skeletal anomalies, such as pubic bone ossification delay, coxa vara or valga, scoliosis, and pectus deformity, were also found in this group of patients. ${ }^{3,4}$

In terms of cognitive development, in our group, like what has been described by Cooper, no significant differences were observed in relation

FIGURE 3. Intrafamily variability in terms of height in one case

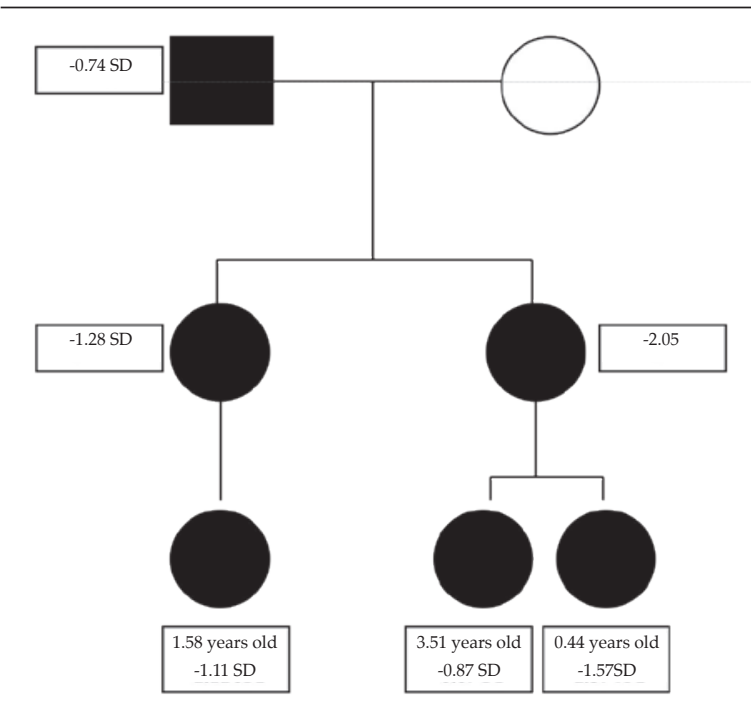

to the level of education achieved by affected individuals and their healthy counterparts. ${ }^{3}$

This pathology is not known as an extremely short stature condition. ${ }^{3}$ In relation to growth, only two patients had IUGR, without other known cause. In spite of the small size of our sample (11 adults), the final height was close to the values reported in the bibliography; for boys, the median height was $162.8 \mathrm{~cm}$ and for girls, $149.2 \mathrm{~cm}$, whereas the bibliography describes $165.0 \mathrm{~cm}$ and $156.0 \mathrm{~cm}$ for boys and girls, respectively. ${ }^{3}$

Some of the patients were short for their genetic height range when their parents were not affected. In addition, one boy had delayed growth and one girl, extremely short stature (-4.28 SD), which has not been reported in the bibliography. In the case of the girl, no other reason for short stature was found; her father was affected but he did not have extremely short stature (162.0 $\mathrm{cm},-1.64 \mathrm{SD})$, which demonstrates intrafamily variability.

In relation to head circumference, only one patient had true macrocephaly, whereas $32.4 \%$ of patients had relative macrocephaly.

No alteration was observed in the body proportions assessed, as sitting height/height ratio, when compared to the Argentine standard. ${ }^{16}$

Our interpretations are limited due to the absence of a molecular analysis, which, in this group, may show molecular variations.

SD: standard deviation.

TABLE 2. Comparative data about the height of affected parents and their children, and among affected siblings

\begin{tabular}{lcccc}
\hline Case & Affected parent's height (SD) & Patient's age (years old) & Patient's height (cm) & Patient's height (SD) \\
\hline 1 & -1.64 & 7.04 & 95.80 & $-4.28^{*}$ \\
2 & -0.74 & 19.00 & 152.90 & -1.28 \\
3 & -0.74 & 19.00 & 148.20 & $-2.05^{*}$ \\
4 & -2.05 & 3.51 & 94.00 & $-0.87^{*}$ \\
5 & -2.05 & 0.44 & 61.00 & -1.57 \\
6 & -1.28 & 1.58 & 78.40 & -1.11 \\
7 & -2.76 & 14.36 & 148.50 & $-1.46^{*}$ \\
8 & -1.40 & 6.43 & 107.80 & -1.85 \\
9 & -2.94 & 0.92 & 67.00 & -3.26 \\
10 & -1.98 & 3.45 & 99.40 & $0.20^{*}$ \\
\hline
\end{tabular}

SD: standard deviation score.

Cases 2, 3, 4, 5, and 6 correspond to members of the same family. Cases 2 and 3 are siblings. Cases 4 and 5 are siblings, and the children of case 3. Case 6 is the child of case 2.

In $5 / 10$ cases, marked with an asterisk $\left(^{*}\right)$, differences were observed between the father/mother's height and that of his/her child of more than 1 SD. It is worth noting the differences among the affected siblings. 


\section{CONCLUSION}

The median height of patients with CCD was within the normal limits; however, both boys and girls were below the $10^{\text {th }}$ height centile and some patients even had mild short stature. In relation to body proportions, no alterations were observed in most patients, although one third had relative macrocephaly. Although few data were available about affected family members, intrafamily variability was observed in terms of height.

\section{REFERENCES}

1. Online Mendelian Inheritance in Man (OMIM $®)$. An online catalog of human genes and genetic disorders. Baltimore (MD): Johns Hopkins University; 1966. [Accessed on: December 17 $\left.7^{\text {th }}, 2016\right]$. Available at: http:/ / omim.org/.

2. Spranger J, Brill P, Nishimura G, et al. Bone Dysplasias: an atlas of genetic disorders of skeletal development. $3^{\text {rd }}$ ed. Oxford: Oxford University; 2012.
3. Cooper SC, Flaitz CM, Johnston DA, et al. A Natural History of Cleidocranial Dysplasia. Am J Med Genet 2001; 104(1):1-6.

4. Machol K, Mendoza-Londono R, Lee B. Cleidocranial Dysplasia Spectrum Disorder. In Adam MP, Ardinger HH, Pagon RA, et al, eds. GeneReviews®. Seatle; University of Washington; 1993-2018.

5. Unger S, Mornet E, Mundlos S, et al. Severe cleidocranial dysplasia can mimic hypophosphatasia. Eur J Pediatr 2002;161(11):623-6.

6. Mundlos S. Cleidocranial dysplasia: clinical and molecular genetics. J Med Genet 1999; 36(3):177-82.

7. Lee B, Thirunavukkarasu K, Zhou L, et al. Missense mutations abolishing DNA binding of the osteoblastspecific transcription factor OSF2 / CBFA1 in cleidocranial dysplasia. Nat Genet 1997; 16(3):307-10.

8. Quack I, Vonderstrass B, Stock M, et al. Mutation analysis of core binding factor $\mathrm{A} 1$ in patients with cleidocranial dysplasia. Am J Hum Genet 1999; 65(5):1268-78.

9. Guo YW, Chiu CY, Liu CL, et al. Novel mutation of RUNX2 gene in a patient with cleidocranial dysplasia. Int J Clin Exp Pathol 2015; 8(1):1057-62.
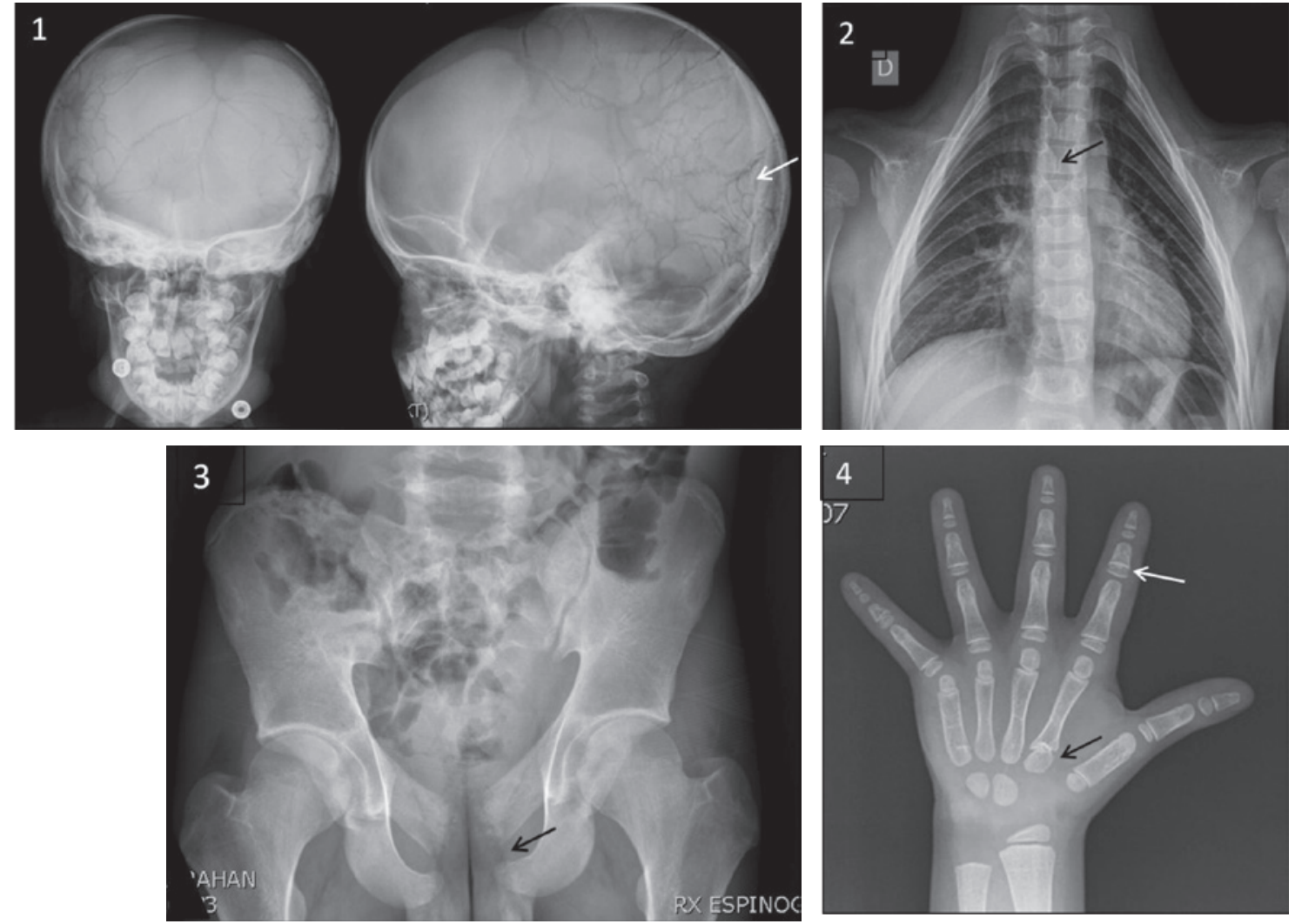

Image 1: skull, front and lateral views. Girl, 5.9 years old. Permeable anterior fontanelle, Wormian bones (thin white arrow), midfacial hypoplasia.

Image 2: chest, front view. Boy, 11.7 years old. Bilateral absence of clavicles. Spinal dysraphism (thin arrow). Image 3: pelvis, front view. Adult male. Lack of ischiopubic branches fusion (thin arrow).

Image 4: left hand, front view. Girl, 6.0 years old. Delayed carpal bone ossification. Pseudoepiphyses of the metacarpal bones (thin arrow).

Cone-shaped epiphyses (thin white arrow). 
10. Zhou G, Chen Y, Zhou L, et al. CBFA1 mutation analysis and functional correlation with phenotypic variability in cleidocranial dysplasia. Hum Mol Genet 1999; 8(12):2311-6.

11. El-Gharbawy AH, Peeden JN Jr, Lachman RS, et al. Severe Cleidocranial dysplasia and Hypophosphatasia in a child with microdeletion of the C-terminal region of RUNX2. Am J Med Genet A 2010; 152A(1):169-74.

12. Morava E, Kárteszi J, Weisenbach J, et al. Cleidocranial dysplasia with decreased bone density and biochemical findings of hypophosphatasia. Eur J Pediatr 2002; 161(11):619-22.

13. Komori T, Yagi H, Nomura S, et al. Targeted Disruption of Cbfa1 Results in a Complete Lack of Bone Formation owing to Maturational Arrest of Osteoblasts. Cell 1997; 89(5):755-64.

14. Comité Nacional de Crecimiento y Desarrollo. Guía para la evaluación del crecimiento físico. Buenos Aires: Sociedad Argentina de Pediatría; 2013.

15. Lejarraga $\mathrm{H}$, del Pino M, Fano V, et al. Referencias de peso y estatura desde el nacimiento hasta la madurez para niñas y niños argentinos: Incorporación de datos de la OMS de 0 a 2 años, recálculo de percentilos para obtención de valores LMS. Arch Argent Pediatr 2009; 107(2):126-33.

16. delPino M, deOrden A, Arenas A, etal.Argentine references for the assessment of body proportions from birth to 17 years of age. Arch Argent Pediatr. 2017;115(3):234-40.

17. Cole TJ, Freeman JV, Preece MA. British 1990 growth reference centiles for weight, height, body mass index and head circumference fitted by maximum penalized likelihood. Stat Med 1998; 17(4):407-29.
18. De Onis M, Onyango AW, Borghi E, et al. Development of a WHO growth reference for school-aged children and adolescents. Bull World Health Organ 2007; 85(9):660-7.

19. WHO multicentre growth reference study group. WHO child growth standards: Length / height for age, weight for age, weight for length, weight for height and body mass index for age: methods and development. Ginebra, World Health Organization, 2006. [Accessed on: July 1 1, 2017]. Available at: www.who.int/childgrowth/standards / Technical_report.pdf.

20. Brook CGD. Clinical Paediatric Endocrinology. $3^{\text {rd }}$ ed. Oxford: Blackwell Science; 1995.

21. Cremin B, Coogman H, Spranger J, et al. Wormian bones in osteogenesis imperfecta and other disorders. Skeletal Radiol 1982; 8(1):35-8.

22. Caffey J, Silverman F. Pediatric X-Ray Diagnosis: a texbook for students and practitioners of pediatrics surgery \& radiology. $5^{\text {th }}$ ed. Chicago: Year Book Medical Publishers; 1967.

23. Caffey J, Madell S. Ossification of the Pubic Bones at Birth. Radiology 1956; 67(3):346-50.

24. Eich GF, Babyn P, Giedion A. Pediatric pelvis: radiographic appearance in various congenital disorders. Radiographics 1992; 12(3):467-84.

25. Golan I, Baumert U, Hrala BP, et al. Dentomaxillofacial variability of cleidocranial dysplasia: clinicoradiological presentation and systematic review. Dentomaxillofac Radiol 2003; 32(6):347-54. 